\title{
1
}

\section{Introduction: The Genesis of a Transnational Collaborative Project}

This book derives from a comparative study of the personal lives of young adult women and their mothers in Hong Kong and Britain (England and Wales) against a backdrop of social change in both societies. Transnational collaborative qualitative research of the kind we describe here is relatively unusual, in part because it presents practical difficulties, not least in financing it, but also because of the parochial, local focus of most social research, especially in western countries. We were fortunate to gain funding from an ESRC Hong Kong Bilateral Award, co-funded by Hong Kong's Research Grants Council (RES-000-22-362). A central element of our bid was to challenge the Eurocentrism of current debates about families, intimacy and social change under late modern social conditions though investigating the lives of two generations of women in one 'western' (British) and one East Asian (Hong Kong) location. We are not simply treating these two locations as isolated examples, or as different modernities, but as part of a web of asymmetrical global interconnections that have produced the condition of the contemporary world variously described as late, second or post-modernity. In this endeavour, we have been influenced by feminist and other critical engagements with theorisations of late modern intimacy (Smart 2007; Heaphy 2007; Jamieson 
2011) and by postcolonial critiques of parochially western theories of modernity (Bhambra 2007, 2014). In this short introduction, we locate ourselves in relation to our project, explain how we came to be collaborators, the intellectual impetus behind our work, what each of us brought to it and the challenges we faced in conducting the research and writing this book.

We first met in May 2004 in Trondheim, Norway, at a conference entitled: 'Heteronormativity: A Fruitful Concept?' We were staying at the same hotel, went sightseeing together and discovered shared research interests in sexuality and intimacy. We stayed in touch and each invited the other to speak at conferences at our home institutions and Stevi then asked Sik Ying to contribute to a book on East Asian sexualities she was co-editing (Jackson et al. 2008). When the ESRC issued a call for bilateral projects with Hong Kong, Stevi saw it as an opportunity to further her interest in East Asian societies and immediately thought of Sik Ying as a potential partner. Thus began a collaboration that has continued and moved on to new projects-and extensive plans for the future. As is usually the case in feminist research, the work we have undertaken together reflects both personal and political investments.

We have both lived through the social changes we describe here. We are of the same generation as the mothers in our sample and represent the two populations whose lives we document-white British and Hong Kong Chinese women. Significantly, too, our own life histories evince the interrelationship between the two locales and the heritage of British colonialism. Stevi, the daughter of a British sailor, spent two years in Hong Kong in one of the most turbulent periods of its history, 1966-1968, when her father was posted to the naval base there (HMS Tamar). As a teenager at the time, Hong Kong made a lasting impression on her and was central to her politicisation. Educated at the British forces' school, St George's, in Kowloon Tong and living in naval quarters in Happy Valley, she could have spent her entire time in the colonial ex-pat community. She chose not to do so, instead making the most of opportunities to see more of Hong Kong and meet local people, shopping in markets in Wanchai and Causeway Bay and enjoying the vibrant, chaotic street life. Hong Kong then was very different from the modern cosmopolitan city of today. Thousands of people lived in squatter settlements, in huts 
constructed out of scraps of wood, corrugated iron and plastic or in overcrowded unsanitary tenements; there were beggars in the streets (then a rare sight in the UK) and informal markets and hawkers everywhere. The rich lived in opulent mansions on The Peak or in Kowloon Tong (where Stevi went to school) and frequented exclusive shops and hotels in the centre of the city. Stevi also learnt about white privilege, which enabled her to observe excessive wealth at close quarters. Although her father was a naval rating, not of the officer class in forces still rigidly class segregated, the fact of being white gave her entry into spaces she could or would never have accessed in the UK. She could go into hotels patronised by the super-rich just to use the toilets, knowing her whiteness would protect her from challenge. She could even to go to entertainment venues at some of these hotels and meet the offspring of the rich and, being white, gain invitations to parties in their homes and even, once, on a yacht, and see at first-hand how they lived. Notably these were the local rich-she could never have 'passed' as of an acceptable class within the social circles of the white colonial elite. The very wide, and very visible, gulf between rich and poor, along with the racial divide and the virulent anti-Chinese racism of most of her British contemporaries, provided Stevi with an object lesson in the evils of colonialism, a lesson that had much to do with her later becoming a sociologist.

In 1967, at the height of the Cultural Revolution in China, Hong Kong erupted in rioting against the colonial regime (see Chapter 2). There had been some riots the previous year over a fare rise on the cross-harbour Star Ferry, but this was something new and different. What started as a labour dispute escalated, led by Maoists leftists in Hong Kong, into mass street demonstrations, which met with considerable force from the authorities with the use of tear gas, baton rounds and live ammunition. Some of the leftists resorted to violent methods, including the use of homemade bombs and weapons. The protests lasted 8 months into early 1968. Stevi recalls travelling to school with grilles on the bus windows and soldiers armed with machine guns as protection as well as bomb disposal teams dealing with three devices placed in or near the naval ratings' housing where she lived (the officers, tucked away in the salubrious neighbourhood of The Peak were less vulnerable). She does not remember being scared, just excited and, while opposed to the 
extremes of violence used, thinking that the protesters had a just cause. This experience, therefore, did not do anything to alter her critical stance on the colonial regime. Her time in Hong Kong planted the seeds of her later interest in East Asian societies. For all its problems, there was much about Hong Kong that she loved and which left her with a deep attachment to it and with a continued-and continuing-concern about its future.

Sik Ying was only eight years old at the time of the disturbances, but one particular memory of them has stuck in her mind, and also tells us something about the contrasting lives led by the local Chinese and even humble members of the British population. At the time Sik Ying's family (her parents, grandmother and 6 children) lived in Sai Ying Pun in one room of an apartment shared with two other families - a contrast with the roomy three-bedroomed flat where Stevi lived with her parents and sister. Sik Ying remembers one tragic and horrific incident from the riots: the death of the radio actor and social commentator Lam Bun, who was attacked by the leftists, doused with petrol and set alight in his car. The reason this mattered to an eight-year old was because of the significance of the serialised radio drama Dai Zengfu (Big/Real Man's Diary), starring Lam Bun, in her daily life. Her mother listened to the show every night at $10 \mathrm{pm}$. She would bribe the children into helping her assemble plastic flowers and toys (factory outwork) by telling them that if they were able to work hard until Dai Zengfu started, they would be rewarded with late supper snacks_-sesame soup, red bean soup and sometimes wonton noodles. As a result of Lam Bun's death, which shocked the family, the much-loved show that had marked the end of their working day was terminated.

Soon after the disturbances, Sik Ying's family moved to a new public housing estate in East Kowloon. She was educated at St Paul's School (Lam Tin), which, like most schools in Hong Kong, was church run, reflecting the colonial context in which Christian organisations and missionaries provided much of the welfare and education for the local population. St Paul's was a school for girls run by the Sisters of St. Paul de Chartres, an order than had been active in Hong Kong since the midnineteenth century. Sik Ying went on to obtain her undergraduate and 
master's degrees at the University of Hong Kong, where she was subsequently employed. It was, therefore, a thoroughly colonial education, modelled on the British system. ${ }^{1}$ Later, as a mature student, Sik Ying went to the UK for postgraduate study, gaining her Ph.D. from the University of Essex in 1996. Overseas education is valued in Hong Kong and in the colonial era British education was seen as the best available. Studying in the UK was also facilitated by the colonial system. Sik Ying's Ph.D. was funded by a Commonwealth Scholarship, by a grant specifically for junior women academics who did not have a Ph.D. She also acquired a British passport as part of a special scheme to discourage educated people from fleeing Hong Kong prior to the 1997 handover to China.

Sik Ying arrived in the UK in the early 1990s, by which time Hong Kong had changed dramatically since the 1960s. It had experienced rapid economic growth with GDP per capita rising substantially year on year from $\$ 714$ in 1968 to $\$ 13,281$ in $1990 .^{2}$ It was still, by this measure, not as wealthy as the UK (with a per capita GDP of $\$ 20,808$ in 1990) ${ }^{3}$ but was now identified as one of the 'Asian Tigers' and no longer as a 'third world' economy. The gulf between rich and poor remained, but the educated middle classes were doing well, enjoying high salaries and the benefits of a technologically advanced consumer society. On arriving in the UK, Sik Ying was shocked to find that the country was so backward, especially technologically. For example, the accommodation office at the Essex University was using pencil to record room bookings and allocation. She found British people polite but rather slow and inefficient after the hard-working fast-paced life in Hong Kong. She also felt that she was richer than her UK peers, could afford expensive designer clothes and long international phone calls to her boyfriend in Holland. Yet at the same time she was disappointed and disoriented by her encounter with the reality of life in Britain. Her English was not as good as she thought, despite being educated through the medium of English since she started secondary school, and she had a Hong Kong accent. Her understanding

\footnotetext{
${ }^{1}$ Hong Kong has recently moved to a school and university system more like that in the USA. ${ }^{2}$ https://countryeconomy.com/gdp/hong-kong?year=1990. Accessed 24 February 2019.

${ }^{3}$ https://countryeconomy.com/gdp/uk. Accessed 24 February 2019.
} 
of western culture was also limited in terms of the common-sense knowhow needed to navigate daily life and interact with the Europeans among whom she was living and studying. She was criticised for what she ate, how much she was able to eat and for remaining slim and felt that Asian women were looked down on. A Danish flatmate told her that she and other Asian women were not taken seriously because they looked too young and lacked confidence in public presentations. Yet despite these setbacks, she adapted and began to enjoy the slower pace of life in the recognition that gaining her Ph.D. would put her on the path to career success - which it ultimately did, while also setting in train the developments whereby her path would cross with Stevi's. Stevi, meanwhile, had been teaching in a post-1992 University throughout the 1980s, when there were very few sociology posts available (see Platt 2003), but in 1993 managed to move to the more established University of Strathclyde, and then, in 1998, secured the Chair in Women's Studies at the University of York. It was here, though teaching and supervising graduate students from East Asia that her interest in that part of the world was rekindled.

Our lives, then, bear testimony to the interconnected histories of Hong Kong and the UK and give us something in common beyond a shared academic interest in intimate relationships. By the time we met, we had each, through different processes, begun to question the hegemony of 'western' knowledge, the ways in which theory generated from Europe and the USA was treated as if it were universal knowledge. Even among feminists keen to acknowledge differences among women and to champion perspectives from the Global South, East Asia was largely ignored. Sik Ying's experiences in the UK had left her well versed in European theory but also, in combination with her life experiences, with a more critical perspective on the western world and its knowledge claims than she had previously been able to develop as a colonised subject. Returning to work at the University of Hong Kong, she could not help but be aware of the theoretical hegemony of western scholarship and ways in which knowledge from beyond the west was treated as peripheral, of only local relevance. Stevi, meanwhile, was striving to cast off the parochial western blinkers that had previously confined the scope of her academic vision and was beginning to see the privileges that her location in the 'west' had afforded her and make connections with the white 
privilege she had enjoyed many years before in Hong Kong. She had learnt from her East Asian graduate students who had also connected her to networks of scholars from the region, enabling her to discover the richness of feminist work being produced there but which was largely unknown in British sociology and women's and gender studies. It was this that precipitated our first meeting in Trondheim. Stevi had noticed that the names of a small group of Hong Kong scholars appeared on the conference programme and wanted to meet them. Spotting a group of Chinese people at breakfast in the hotel she took a chance and walked over to their table, asked if they were the delegates from Hong Kong (they were) and introduced herself.

We started working together on the proposal for the project in 2009, began to plan the research in 2010 and conducted the fieldwork over the next eighteen months. It was in some ways opportunistic, a response to a funding call that offered a rare opportunity for collaboration between UK and Hong Kong scholars. It was not, however, only opportunistic, as we had a genuine intellectual aim: to do work that challenged western knowledge claims. Even so, the UK and Hong Kong may seem odd cases for comparison as one is a nation and the other is a Special Administrative Region of China. ${ }^{4}$ This asymmetrical relationship, however, is part of what makes the comparison of interest. As our personal biographical narratives indicate, these two societies are a product of their interconnected histories and, as we will argue later, of the wider global connections that shaped the modern world.

Working together was not always easy or straightforward. Although we had stayed in touch over the intervening years since our first meeting, we did not know each other very well when we began the project and there was, therefore, a certain degree of risk in collaborating and in not fully understanding each other's approach to research or the intellectual baggage we each brought to it. It was very much a learning experience for both of us. We had slightly different intellectual agendas, differing theoretical and methodological concerns and intellectual histories in addition to our specific cultural locations. This affected what we each brought

\footnotetext{
${ }^{4}$ While here we use 'UK' in discussing the relationship between the two territories, elsewhere we deliberately use 'Britain' and 'British' since all the UK interviews were conducted in England and Wales rather than in the UK as a whole.
} 
to the research collaboration and how we undertook both the fieldwork and analysis. While Stevi was primarily interested in the changes in the lives of two generations of women in relation to theoretical debates on modernity and intimacy, Sik Ying was more concerned with and attentive to mother-daughter relationships. Both preoccupations are evident in the final form this book has taken.

Both of us, however, always been interested in the everyday, the ways in which personal lives and intimate relationships are conducted within particular sociocultural and political contexts and how individuals make sense of their lives in those contexts. Working collaboratively across cultures has broadened our understanding of the complexity of the everyday and sensitised us to the importance of thinking not only about cultural differences, but also about the material socio-economic conditions and political circumstances in which our intimate and family relationships take shape. Collaborative working across cultures has also sensitised us to local specificities, leading each of us to question what we take for granted and make our own familiar strange-as when we find we have to explain aspects of our local cultures and conditions to each other.

Attending to local specificities has also prompted us to think critically about the methodological and conceptual choices involved in doing comparative research. In particular, it is vital to do comparison symmetrically, not taking 'the west' as the benchmark against which others' sexual mores and family practices are evaluated. In making comparisons and accounting for differences across the world we should not simply attribute such differences to culture or tradition, but also take account of wider historical, social, economic and political conditions through which cultural continuity and change are mediated. We should certainly not assume that there is a universal trajectory of 'progress' that all are travelling along, with some leading the way while others lag behind. We should avoid thinking of 'them' and 'us', the all too easy 'othering' of places outside the metropole. This means staying alert to the limitations of theories generated from western locations and the difficulty of having voices from the global periphery heard in what counts as the academic mainstream. As Raewyn Connell points out, in 'the era of neoliberal globalization, the metropole continues to be the main site of theoretical processing' affecting how scholars the world over do their work, so that the metropole's 
theoretical hegemony has become 'the normal functioning of this economy of knowledge' (Connell 2015: 51). Issues of language and the conceptual possibilities it enables and delimits are part of this. In working together on Cantonese language data, as, respectively, native English and Cantonese speakers writing for an international audience, we are constantly trying to capture the nuances of expression in a Chinese language and make them intelligible to an Anglophone audience. We are then constrained to effect a further translation into the conceptual language of Euro-American scholarly convention. We hope this book will contribute to critical scholarship and to internationalising feminist and sociological knowledge, which requires attention to the range of issues we have raised: material socio-economic contexts, colonial legacies and western conceptual and Anglophone linguistic hegemony (see Jackson et al. 2017; Jackson and Ho 2018).

Since we completed our fieldwork with mothers and daughters, the world has continued to undergo change. There has been much conflict on the global stage as well as the rise of populist political movements and increasingly autocratic regimes in states that are ostensibly democratic. The UK and Hong Kong have had their share of political strife-in the former over Brexit and in the latter the ongoing struggle for democracy, freedom and human rights. In Hong Kong the political turbulence, ongoing as we complete this book, has been particularly acute and was unforeseen when we began work on this project. Hong Kong needs to be understood in relation to China as well as in relation to its past colonial ties to the UK; both have shaped its particular conditions of life. When we began our research, conditions in China seemed to be becoming more liberal, but the PRC's regime has grown increasingly authoritarian since $\mathrm{Xi}$ Jinping came to power in 2012. Rigorous censorship has limited the research that can be conducted on and in China and is threatening academic freedom in Hong Kong (Ho et al. 2018a). The revival of Confucianism in China and its emphasis on the centrality of the family to social stability is also being felt in Hong Kong through attempts to extend Chinese style 'national and moral education' to Hong Kong. The tightening hold of Beijing over Hong Kong's local governance and, in particular, the denial of the democracy promised at the handover, led to a major popular uprising, the Umbrella Movement, in the autumn of 2014 and 
ultimately to the protests that began in the summer of 2019. These later protests were sparked by a bill (now withdrawn) allowing extradition of alleged criminals to mainland China but have broadened into wider prodemocracy activism. The reverberations of the Umbrella Movement, as our recent research demonstrates, had an impact on personal and family life (see Ho et al. 2018b, c), which prompts us to think about the future consequences of the 2019-2020 struggles, intensified early in 2020 by the coronavirus outbreak. These political developments, because of their urgency and immediacy, absorbed much of our energy and diverted us away from completing work on this book. At the same time, however, they offered us new insights and cast new light on the data we had gathered from our sample of mothers and daughters. Where relevant we use some of our more recent research in what follows to complement our earlier findings on Hong Kong family life.

In the next chapter, we begin to explore and elaborate on the issues outlined above by discussing the theoretical and methodological framework of our study and then introducing our participants. In the following chapter, we set the lives of women in Britain and Hong Kong in historical context, emphasising the interconnections between the UK, China and Hong Kong that have shaped those lives. We might think that this matters only for Hong Kong, but it does not; Britain's past empire, we will argue, shaped the 'home country' as much as its colonies. In surveying this history, we will use accounts from the women we interviewed, particularly the older generation, to demonstrate the changes that have occurred in the social life of each location since the end of the Asia Pacific War and the Second World War.

In the fourth chapter, we address the central issue of our study: the diverse forms of family life in our two locations, the meaning 'family' has for our participants and the practices associated with it. This emphasis on family practices carries over into the following chapter (Chapter 5) where we make use of the concept of 'practices of intimacy' (Jamieson 2011) to analyse the relationships between mothers and daughters and how they have been sustained from the daughters' childhoods into their young adulthood. The sixth chapter charts the romantic and sexual relationship trajectories of both generations of women, focusing how social change and sociocultural differences have shaped women's partnership 
choices. We look to the imagined futures of the daughters in Chapter 7 , bringing our attention back to notions of tradition and modernity in young women's aspirations. In our final, brief, concluding chapter we reflect again on theories of modernity and how modernity is lived and experienced in specific contexts.

Throughout the book, in making comparisons and accounting for differences between the two locales, we subject ideas of 'cultural' and 'traditional' differences to critical scrutiny and continually emphasise the importance of social, economic and political conditions through which continuity and change are mediated. This is a major strength of undertaking comparative research. Even when done on a relatively small scale, as in this study, it serves to demonstrate the social shaping of individual lives by attending to the varied ways that intimacy can be practised, family lives can be lived and gender relations can be constituted in differing circumstances. In detailing the lives of the women who participated in our study and the ways they told their stories to us, we also pay attention to their relational constructions of gendered selfhood within the forms of subjectivity available to them in changing times and in their specific locales. We see our analysis as exercising a feminist sociological imagination, which 'enables us to grasp history and biography and the relation between the two in society' (Mills 1970: 12), in this case in two very different societies with intertwined histories. 